\title{
Differential conditioning can reverse the fear-reducing effects of phenobarbital
}

\author{
DONALD A. OVERTON \\ Temple University School of Medicine, Philadelphia, Pennsylvania
}

\begin{abstract}
Rats were trained in a conditioned emotional response (CER) task in which barpressing for saccharine solution was suppressed during a tone conditioned stimulus which sometimes signalled imminent electric shock. Phenobarbital $80 \mathrm{mg} / \mathrm{kg}$ was administered before sessions 2 , 4,6 , etc., and isotonic saline before alternate sessions. To establish a discriminated CER, tone was paired with shock only during drug sessions in Group 1, and only during no drug sessions in Group 2. This differential conditioning procedure made suppression of bar pressing conditional on the presence of phenobarbital in Group 1, and on its absence in Group 2. The results suggest that discriminated responding controlled by drug stimuli could either augment or reduce the fear-reducing effects of phenobarbital.
\end{abstract}

Many reports have attempted to clarify the intrinsic (pharmacologically determined) effects of psychoactive drugs on experimentally induced anxiety. Several of these studies have used a "conditioned emotional response" (CER) task in which ongoing barpressing maintained by food or water reinforcement was suppressed during a conditioned stimulus (CS) that heralded the imminent delivery of the unconditioned stimulus (US), electric shock (Hunt, 1956). The results of such studies have indicated that barbiturates reduce the amount of fear induced by the CS (Millenson \& Leslie, 1974; Miller, 1961).

In a separate series of "drug discrimination" experiments, rats have been reinforced for performing one instrumental response while drugged (e.g., right turn in a T-maze) and a different response while undrugged (left turn). With antianxiety drugs, differential responding has been readily obtained in a variety of tasks (Overton, 1971). This has led investigators to state that antianxiety drugs have strong, or readily discriminated, "stimulus" effects that provide the basis for control of differential responding.

The present experiment tested whether conditioned suppression in the CER task could be made contingent upon the presence (or absence) of phenobarbital by consistently pairing drug administration with shock (or with its absence). Because phenobarbital has anxietyreducing effects, the experiment can be viewed as testing whether these intrinsic fear-reducing actions of the

This research was partially reported at the meeting of the Eastern Psychological Association, Boston, Massachusetts, 1972. This study was supported by NIMH Grant MH-25136 and by NIDA Grant DA-02403. I wish to thank Beverly Lange, Judith Stofman, and Purabi Dutta for technical assistance. Requests for reprints should be addressed to Donald Overton, Psychiatry Department, Temple Medical School, 3401 N. Broad Street, Philadelphia, Pennsylvania 19140. drug could be accentuated and/or overridden by discrimination training.

\section{METHOD}

\section{Subjects}

Hooded male rats weighing about $200 \mathrm{~g}$ each at the beginning of training were maintained on a $23-\mathrm{h}$ water-deprivation schedule under which they received $25 \mathrm{cc}$ of water in the home cage immediately after testing and had dry food available ad lib.

\section{Drugs}

Sodium phenobarbital was dissolved in isotonic saline and injected intraperitoneally in a volume of $1 \mathrm{ml} / \mathrm{kg} 20 \mathrm{~min}$ before "drug" sessions. A high dose $(80 \mathrm{mg} / \mathrm{kg})$ was employed because we had previously failed to obtain a discriminated CER in an experiment that utilized $40 \mathrm{mg} / \mathrm{kg}$ in albino rats.

\section{Apparatus}

The training compartment measured $20 \times 30 \times 18 \mathrm{~cm}$ and was constructed of Lucite and aluminum. The floor consisted of steel rods $5 \mathrm{~mm}$ in diameter spaced $2 \mathrm{~cm}$ apart. A lever manipulandum and a water-delivery magazine were located on the wall at one end of the chamber. Each reinforcement consisted of $0.1 \mathrm{cc}$ of $1 \%$ saccharine solution delivered by a solenoid valve that produced a clearly audible click on delivery. Panel lights located above the bar and above the water-delivery magazine flashed briefly whenever the bar was pressed or when water was delivered. The CS was a $30-\sec 2500-\mathrm{Hz}$ tone generated by a Sonalert device. The US was a $60-\mathrm{Hz} 0.35-\mathrm{mA}$ shock lasting $0.5 \mathrm{sec}$ produced by a transformer scrambler ${ }^{1}$ and delivered via the grid floor. The training chamber was enclosed in a lightproof sound-attenuating enclosure. Ventilation, a masking noise, and a 7-W houselight were provided. Electromechanical control equipment was located remotely.

\section{Behavioral Procedures}

The rats were placed on a 23-h water-deprivation schedule for 1 week, magazine trained, shaped to press a bar using sweetened water as a reinforcer, and shifted to a variable-interval 30 -sec (VI-30) schedule (averaging $30 \mathrm{sec}$ between reinforced responses). Training sessions with the VI-30 schedule were continued for 3-4 weeks until response rates had stabilized. Phenobarbital $(80 \mathrm{mg} / \mathrm{kg})$ was administered before some of these sessions to accustom the rats to responding while drugged. About $50 \%$ 
of the rats failed to respond when this high dose was administered and were removed from the experiment. Training sessions took place at midday during the light phase of a noninverted light/dark cycle and were $23 \mathrm{~min}$ in duration.

After the rate of pressing had stabilized, the rats received eight baseline (tone-adaptation) sessions during which a $30-\mathrm{sec}$ tone was presented twice during each session. Phenobarbital was injected before half of these baseline sessions to determine its effects on rate of responding and to habituate the rats to the tone in both the D (drug) and N (no drug) conditions. Discrimination training began the day after the last baseline session.

During discrimination training, tone was consistently paired with shock in one drug condition and was never paired with shock in the other drug condition. The rats received daily 23-min sessions, each containing two $30-\mathrm{sec}$ tone presentations that began 10.5 and $16.5 \mathrm{~min}$ after the start of the session. Phenobarbital was administered intraperitoneally 20 -min before every second training session, and the saline vehicle was administered before alternate sessions. Four rats in Group 1 received shock during sessions preceded by phenobarbital injection; six rats in Group 2 received shock during sessions preceded by saline injection. The footshock US, when administered, was contiguous with the last $0.5 \mathrm{sec}$ of the tone presentations.

\section{Data Analysis}

The number of presses during the 30-sec epochs before and during each tone was used to compute the amount of suppression of pressing during the CS. An inflection ratio (IR) for each session was computed according to the equation $I R=(B 1+B 2-A 1-A 2) /(B 1+B 2)$, where $B$ is barpresses during the $30 \mathrm{sec}$ before tone, $\mathrm{A}$ is presses during the tone, and 1 and 2 designate the first and second tone presentations. With this computation, IR $=1$ indicates complete suppression of barpressing during the tone $\mathrm{CS}$, and $\mathrm{IR}=0$ indicates no suppression.

\section{RESULTS}

The inflection ratios in Figure 1 show the gradual onset of discriminated suppression of barpressing. Figures $1 \mathrm{~A}$ and $1 \mathrm{~B}$ show that IRs for individual rats varied considerably from day to day due to "noise" that resulted from the small number of responses used to compute the inflection ratios. Figures 1C and 1D show group mean inflection ratios (Rat 116 is excluded from
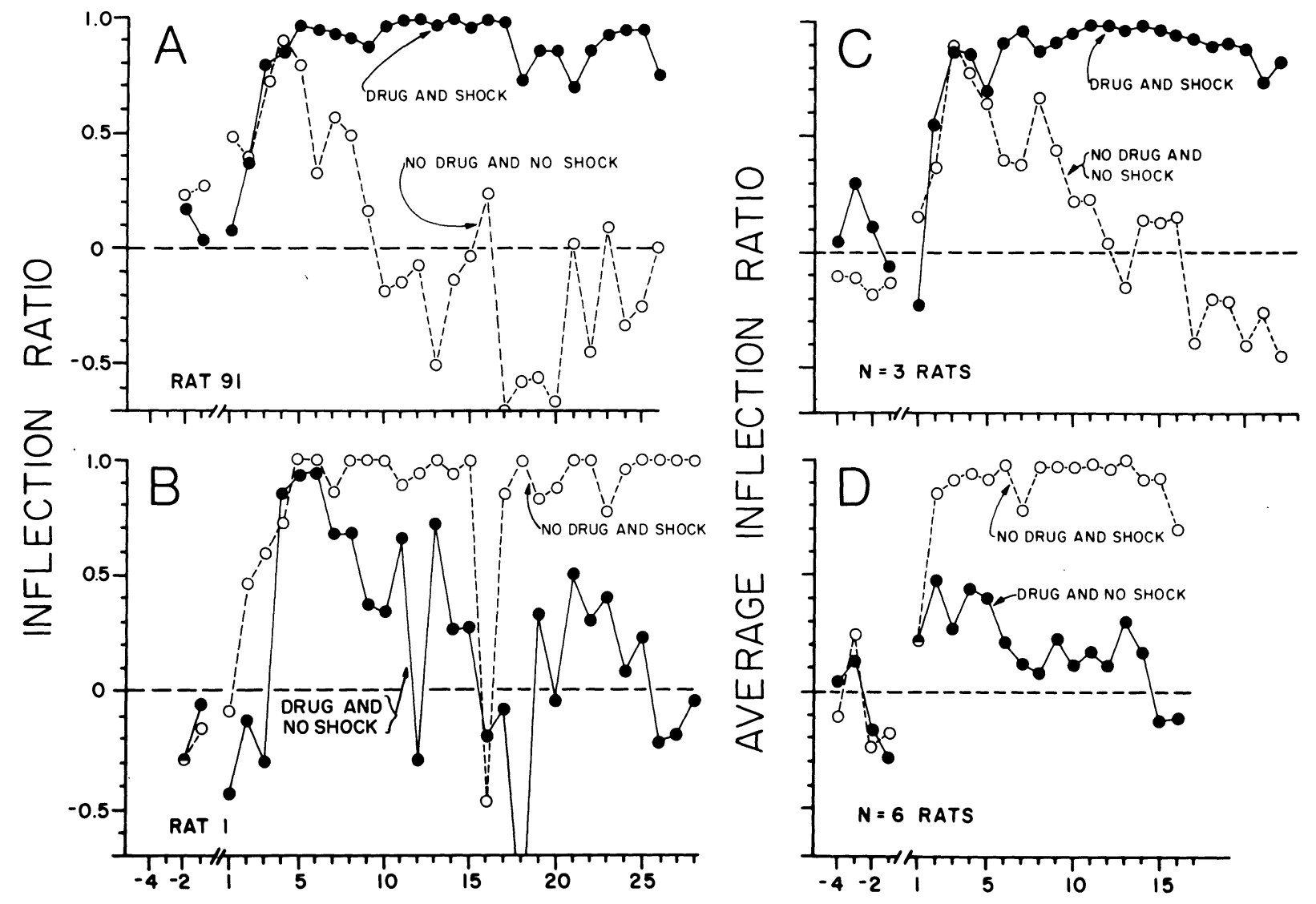

SUCCESSIVE BLOCK OF SESSIONS

Figure 1. Inflection ratios during successive sessions show the extent to which barpressing slowed down during the tone CS. Drug and no-drug sessions are plotted separately. Each unit on the $x$-axis represents two drug and two no-drug sessions. Panels $A$ and $B$ show inflection ratios for individual animals, averaged across the four tone presentations that occurred during two successive drug or no-drug sessions. Panels $C$ and $D$ show average inflection ratios for each group. In Panel $C$, any fear-reducing effect of phenobarbital was eliminated by the training procedure, and the rats showed fear during drug sessions (i.e., stopped pressing during tone) but showed no fear during no drug sessions. 
the average curve in Figure 1C). In these plots, IRs were near zero during sessions before shock was introduced, indicating that tone did not alter barpressing rates prior to CS-US pairing. During the first 12 sessions after introduction of shock, inflection ratios rose in both drug conditions, thus reflecting suppression of responding during the CS. During the following 60 sessions, inflection ratios remained near unity in the shock condition, but gradually returned to zero during sessions in which no shock was administered. Differential responding developed most rapidly in the no-drug/shock group (Figure 1D).

Table 1 shows mean rates of pressing in each drug condition before and during tone presentations during eight baseline sessions and during Sessions 41 to 70 of discrimination training. During baseline sessions, tone had little effect on the rate of pressing, except in Rat 91 during $\mathrm{N}$ sessions. During the early shock-training sessions, overall rates became quite low in some rats, possibly indicating that fear of shock was not restricted to the period in which tone was present (data for early training sessions are not shown in Table 1). Table 1 shows that, after 40 sessions of discrimination training, rates of pressing during tone were near zero in the shock condition for most rats and were similar to rates before tone in the no-shock condition. There were no consistent differences between rates during the first and second tone presentations of the sessions. Performance by Rat 116 differed radically from that of all other animals: it consistently showed low rates during tone in both drug and no-drug sessions. Due to a procedural error, Rat 116 was shocked during Session 61 (no drug), which may have retarded development of discriminated responding. Table 1 shows that, after training, three of the four rats in Group 1 suppressed pressing more in the shock-associated condition than in the no-shock condition. In Group 2, all six rats showed this pattern of responding. Such results are unlikely to have occurred by chance $(p=0.033$, Fisher exact test).

\section{DISCUSSION}

The results suggest that a discriminated CER conditional on either the presence or absence of phenobarbital could be established. This result is significant not primarily because the expected drug discrimination was established, but because the experimental paradigm was structured in such a way that the learned response could either enhance or attenuate the normal fear-reducing effects of phenobarbital.

The CER became conditional on drug state in Group 1 only after more prolonged training than is required in two-response drug-discrimination tasks, in which reinforcement is explicitly contingent upon differential responding. Perhaps the discrimination was learned slowly because reinforcement was not contingent on differential responding; only extinction was used to attenuate the CER in the unshocked condition. Equally slow acquisition was also reported recently by Haug and Gotestam (1981) in an experiment very similar to the present one.

The CER was not strongly state dependent and did generalize into the no-shock condition during early training sessions in Group 2. This result differs from that obtained by Heistad and Torres (1959), who reported state-dependent learning effects in the CER task with reserpine, a drug with weaker "stimulus effects" than those of phenobarbital (Overton, 1982). However, the present results are concordant with those of Duncan (1979), who found measurable SDL amnesias in a CER task only when special testing procedures were employed, indicating that SDL effects are weak in the CER task.

Differential responding in Group 2 may have been based at least partially on phenobarbital's fear-reducing effects, since suppression of pressing was minimal during drug sessions even early in training, presumably before the drug discrimination was learned. The experimental design was flawed by omission of a control group in which shock was paired with tone on both D

Table 1

Rates of Barpressing Before and During Tone Presentations, Before and After Discrimination Training

\begin{tabular}{|c|c|c|c|c|c|c|c|c|c|c|c|c|}
\hline \multirow[b]{3}{*}{ Rat } & \multicolumn{4}{|c|}{ Baseline Rates } & \multicolumn{8}{|c|}{ Average Rates During Sessions 41-70 } \\
\hline & \multicolumn{2}{|c|}{ Drug Sessions } & \multicolumn{2}{|c|}{ No-Drug Sessions } & \multicolumn{4}{|c|}{ Drug Sessions } & \multicolumn{4}{|c|}{ No-Drug Sessions } \\
\hline & $\begin{array}{l}\text { Before } \\
\text { Tones }\end{array}$ & $\begin{array}{l}\text { During } \\
\text { Tones }\end{array}$ & $\begin{array}{l}\text { Before } \\
\text { Tones }\end{array}$ & $\begin{array}{c}\text { During } \\
\text { Tones }\end{array}$ & $\begin{array}{l}\text { Before } \\
\text { Tone } 1 \\
\end{array}$ & $\begin{array}{l}\text { Before } \\
\text { Tone } 2 \\
\end{array}$ & $\begin{array}{l}\text { During } \\
\text { Tone } 1 \\
\end{array}$ & $\begin{array}{l}\text { During } \\
\text { Tone } 2 \\
\end{array}$ & $\begin{array}{l}\text { Before } \\
\text { Tone } 1 \\
\end{array}$ & $\begin{array}{c}\text { Before } \\
\text { Tone } 2 \\
\end{array}$ & $\begin{array}{l}\text { During } \\
\text { Tone } 1 \\
\end{array}$ & $\begin{array}{l}\text { During } \\
\text { Tone } 2 \\
\end{array}$ \\
\hline \multicolumn{13}{|c|}{ Group 1: D-Shock; N-No Shock } \\
\hline $\begin{array}{r}91 \\
113 \\
116 \\
118\end{array}$ & $\begin{array}{l}17 \\
20 \\
29 \\
49\end{array}$ & $\begin{array}{l}16 \\
19 \\
31 \\
45\end{array}$ & $\begin{array}{l}15 \\
37 \\
28 \\
30\end{array}$ & $\begin{array}{r}9 \\
37 \\
28 \\
36\end{array}$ & $\begin{array}{l}28 \\
32 \\
37 \\
65\end{array}$ & $\begin{array}{l}28 \\
26 \\
33 \\
58\end{array}$ & $\begin{array}{l}1 \\
3 \\
3 \\
1\end{array}$ & $\begin{array}{l}1 \\
2 \\
6 \\
1\end{array}$ & $\begin{array}{l}20 \\
27 \\
33 \\
41\end{array}$ & $\begin{array}{l}22 \\
32 \\
29 \\
50\end{array}$ & $\begin{array}{r}21 \\
21 \\
3 \\
44\end{array}$ & $\begin{array}{r}25 \\
40 \\
6 \\
44\end{array}$ \\
\hline Mean & 28.8 & 27.8 & 27.3 & 27.6 & 40.3 & 36.3 & 2.0 & 2.7 & 30.1 & 33.4 & 22.2 & 28.7 \\
\hline \multicolumn{13}{|c|}{ Group 2: D-No Shock; N-Shock } \\
\hline $\begin{array}{r}95 \\
96 \\
111 \\
112 \\
114 \\
115\end{array}$ & $\begin{array}{l}17 \\
10 \\
14 \\
50 \\
46 \\
34\end{array}$ & $\begin{array}{l}21 \\
11 \\
18 \\
44 \\
38 \\
45\end{array}$ & $\begin{array}{l}27 \\
11 \\
47 \\
52 \\
42 \\
75\end{array}$ & $\begin{array}{l}37 \\
15 \\
45 \\
57 \\
56 \\
61\end{array}$ & $\begin{array}{l}21 \\
17 \\
40 \\
47 \\
41 \\
51\end{array}$ & $\begin{array}{l}16 \\
18 \\
31 \\
40 \\
36 \\
45\end{array}$ & $\begin{array}{l}13 \\
13 \\
30 \\
31 \\
40 \\
45\end{array}$ & $\begin{array}{l}13 \\
16 \\
31 \\
26 \\
35 \\
44\end{array}$ & $\begin{array}{l}15 \\
11 \\
22 \\
38 \\
29 \\
85\end{array}$ & $\begin{array}{l}16 \\
12 \\
21 \\
39 \\
33 \\
86\end{array}$ & $\begin{array}{l}3 \\
1 \\
0 \\
1 \\
2 \\
4\end{array}$ & $\begin{array}{l}2 \\
1 \\
0 \\
1 \\
4 \\
5\end{array}$ \\
\hline Mean & 28.0 & 29.3 & 42.3 & 45.2 & 36.1 & 30.8 & 28.4 & 27.4 & 33.4 & 34.6 & 2.4 & 2.1 \\
\hline
\end{tabular}

Note-To characterize performance after discrimination training, the table shows rates of pressing during the 5.5 min preceding each tone and during each 30-sec tone, averaged across Sessions 41-70, separately for drug and no-drug sessions and separately for the first and second tone presentations. For the 8 baseline sessions before discrimination training, the table shows rates averaged across the two tone presentations in each session. 
and $\mathrm{N}$ days. Without this control group, we cannot say with certainty that a drug discrimination was learned in both groups. Conceivably, the differential suppression shown by Group 2 may have been based entirely on the fear-reducing effects of phenobarbital, with no discrimination ever being learned. However, Group 1 learned to suppress barpressing under phenobarbital, whereas pressing continued in the absence of the drug. In this case, a discrimination clearly was learned, and the normal fear-reducing effects of phenobarbital appear to have been overridden by the effects of training so that the CS drug-plus-tone became a fear-inducing stimulus in the CER training compartment.

Three other limitations in the experimental design should be considered. First, we used a relatively high dose of phenobarbital and hence had to eliminate about $50 \%$ of the more drug-sensitive rats from the experiment. It is not certain that results comparable to ours would have been obtained with the excluded animals. Second, the use of a simple alternation training procedure (DNDN ...) makes it conceivable that the rats learned to alternate their responses on successive sessions without reference to the imposed D and $\mathrm{N}$ conditions. Some of our data bear on this possibility. Due to procedural mishaps, rats received sessions that did not follow the normal alternating NDND sequence on several occasions. None of these procedural variations caused any disruption of discriminated suppression during the ensuing training sessions. Additionally, Haug and Gotestam (1981), who used a double-alternation sequence of training conditions (NNDD ...), also obtained a discriminated CER. Third is the possibility that relatively complete tolerance to the fear-reducing effects of phenobarbital had developed by the time that discriminated suppression appeared in Group 1. We did not test this possibility.

Turner and Altshuler (1976) reported that a drug could act as a CS in a classical conditioning paradigm. In their study, footshock was administered on days when the rats were drugged. Subsequent tests in a different test compartment indicated that the drug acted as a CS eliciting conditioned fear (suppression of barpressing). They used stimulant drugs, which may enhance suppression of pressing as an unconditioned action (Brady, 1956). Nonetheless, their results strongly suggest that conditioned suppression of pressing was a CR to the drug in their rats. Their result is interesting, because it indicates that a drug can acquire essentially a new effect as the result of a conditioning paradigm. Presumably, this learned effect may summate with, block, or be unrelated to the intrinsic effects of the drug.

Although the CER commonly is considered to be a classically conditioned response, it is unclear in the present experiment whether the drug can best be regarded as a CS for fear in Group 1 (Cook, Davidson, Davis, \& Kelleher, 1960) or should instead be regarded as part of a compound discriminative stimulus (toneplus-drug). As a related question, one can ask whether the acquired significance of phenobarbital would alter its actions outside the CER task. The data bear on this question. Rates of pressing prior to tone in Group 1 during drug sessions were not decreased by conditioning. This indicates that only the toneplus-drug combination became a signal for fear. The simple presence of phenobarbital did not appear to induce fear within the CER task and, by extrapolation, probably would not have done so in other test environments. This pattern of results is probably best described by considering the drug to be a discriminative stimulus rather than a CS for fear.
The present results have two interesting inplications. First, they suggest that learned modifications of drug effects might be inadvertently produced in experiments in which drug effects are repeatedly tested under extinction conditions with interspersed no-drug retraining. In such circumstances, animals might learn to respond differentially under the drug because extinction contingencies would be associated with the drug; this might lead an investigator to draw incorrect conclusions about the drug's effects. Second, the results suggest that drug effects might be accidentally altered in some clinical situations, for example, if drug administration was regularly paired with some anxietyinducing event.

\section{REFERENCES}

Brady, J. V. (1956). Assessment of drug effects on emotional behavior. Science, 123, 1033-1034.

Cook, L., Davidson, A., Davis, D. J., \& Kelleher, R. T. (1960). Epinephrine, norepinephrine and acetylcholine as conditioned stimuli for avoidance behavior. Science, 131, 990-991.

Duncan, P. M. (1979). The effect of external stimulus change on ethanol-produced dissociation. Pharmacology, Biochemistry \& Behavior, 11, 377-381.

Haug, T., \& Gotestam, K. G. (1981). Two opposite effects of diazepam on fear by differential training in the CER paradigm. Psychopharmacology, 75, 110-113.

Heistad, G. T., \& Torres, A. A. (1959). A mechanism for the effect of a tranquilizing drug on learned emotional responses. University of Minnesota Medical Bulletin, 30, 518-527.

HunT, H. F. (1956). Some effects of drugs on classical (type S) conditioning. Annals of the New York Academy of Sciences, 65, 258-267.

Millenson, J. R., \& Leslie, J. (1974). The conditioned emotional response (CER) as a baseline for the study of anti-anxiety drugs. Neuropharmacology, 13, 1-9.

Miller, N. E. (1961). Some recent studies of conflict behavior and drugs. American Psychologist, 16, 12-24.

Overton, D. A. (1971). Discriminative control of behavior by drug states. In T. Thompson \& R. Pickens (Eds.), Stimulus properties of drugs. New York: Appleton-Century-Crofts.

Overton, D. A. (1982). Comparison of the degree of discriminability of various drugs using the T-maze drug discrimination paradigm. Psychopharmacology, 76, 385-395.

Turner, E. G., \& Altshuler, H. L. (1976). Conditioned suppression of an oprant response using d-amphetamine as the conditioned stimulus. Psychopharmacology, 50, 139-143.

\section{NOTE}

1. This type of shock scrambler is simple and inexpensive. Four transformer secondary windings $(\mathrm{W})$ are connected in series with four current-limiting resistors $(R)$ to provide five output wires (O). The wiring sequence is ORWOWRORWOWRO. In practice two transformers with center-tapped $500-\mathrm{V}$ ac secondary windings can be used in conjunction with four $500,000-\mathrm{ohm}$ resistors to produce a $0.5-\mathrm{mA}$ current between any two of the five output terminals. High voltages result from connecting the secondary windings in series in this fashion; these voltages may be dangerous to personnel.

(Manuscript received for publication September 22, 1983.) 